\title{
How Much Will the Belt and Road Initiative Reduce Trade Costs?
}

de Soyres, François, Alen Mulabdic, Siobhan Murray, Nadia Rocha, and Michele Ruta

Please cite paper as:

de Soyres, François, Alen Mulabdic, Siobhan Murray, Nadia

Rocha, and Michele Ruta (2020). How Much Will the Belt and

Road Initiative Reduce Trade Costs? International Finance

Discussion Papers 1274.

https://doi.org/10.17016/IFDP.2020.1274

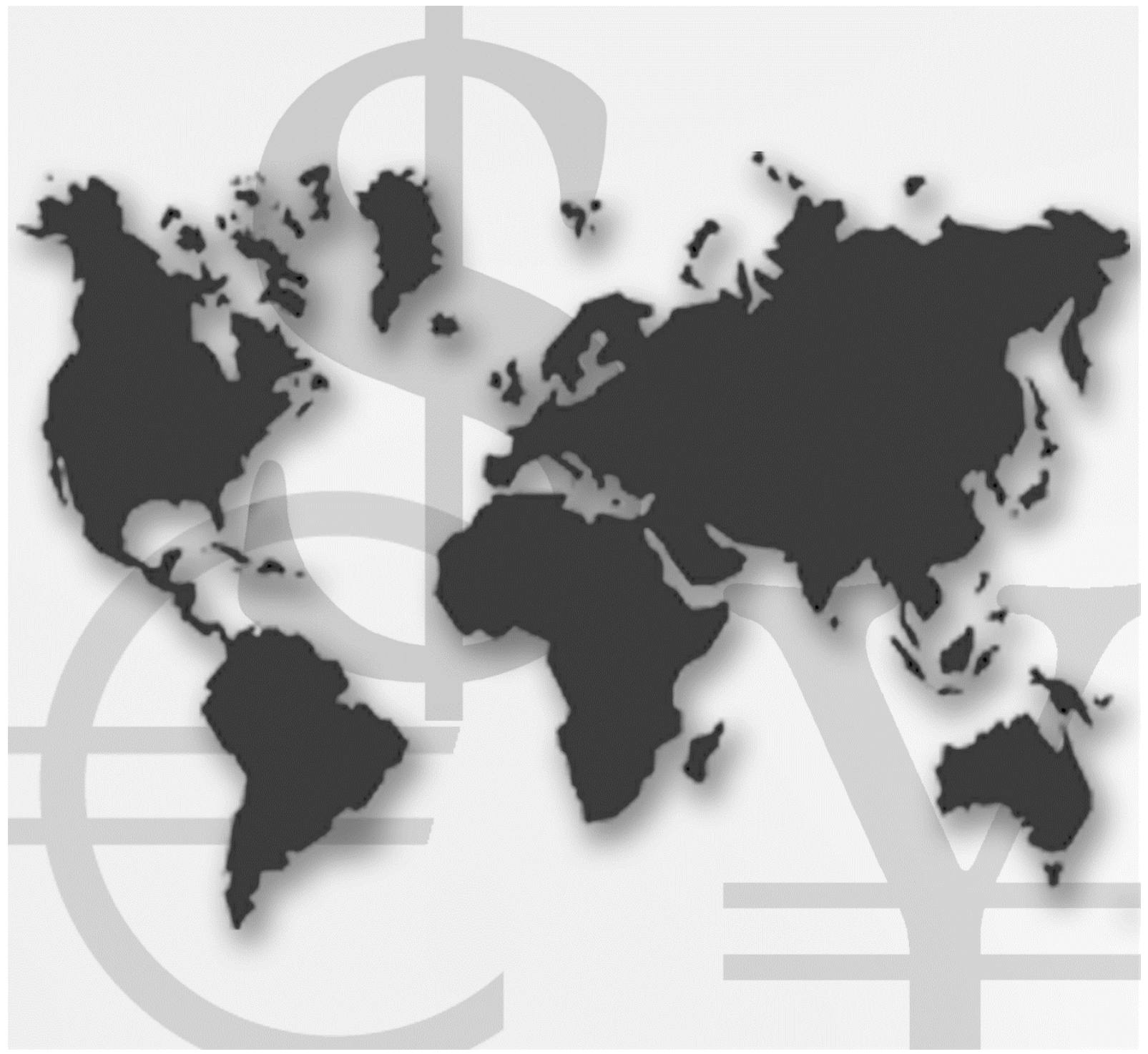

\section{International Finance Discussion Papers}

Board of Governors of the Federal Reserve System

Number 1274

February 2020 
Board of Governors of the Federal Reserve System

International Finance Discussion Papers

Number 1274

February 2020

\section{How Much Will the Belt and Road Initiative Reduce Trade Costs?}

François de Soyres, Alen Mulabdic, Siobhan Murray, Nadia Rocha, and Michele Ruta

NOTE: International Finance Discussion Papers (IFDPs) are preliminary materials circulated to stimulate discussion and critical comment. The analysis and conclusions set forth are those of the authors and do not indicate concurrence by other members of the research staff or the Board of Governors. References in publications to the International Finance Discussion Papers Series (other than acknowledgement) should be cleared with the author(s) to protect the tentative character of these papers. Recent IFDPs are available on the Web at www.federalreserve.gov/pubs/ifdp/. This paper can be downloaded without charge from the Social Science Research Network electronic library at www.ssrn.com. 


\title{
How Much Will the Belt and Road Initiative Reduce Trade Costs? ${ }^{1}$
}

\author{
See the published version on International Economics website HERE.
}

François de Soyres, Alen Mulabdic, Siobhan Murray, Nadia Rocha and Michele Ruta

\begin{abstract}
This paper studies the impact of transport infrastructure projects of the Belt and Road Initiative on shipment times and trade costs. Based on a new data on completed and planned Belt and Road transport projects, Geographic Information System analysis is used to estimate shipment times before and after the Belt and Road Initiative. Two sets of data are computed to address different research questions: a global database based on an analysis of 1,000 cities in 191 countries and 47 sectors and a regional database that focuses on more granular information (1,818 cities) for Belt and Road economies only. The paper uses sectoral estimates of "value of time" to transform changes in shipment times into changes in ad valorem trade costs at the country-sector level. The findings show that the Belt and Road Initiative will significantly reduce shipment times and trade costs. For the world, the average reduction in shipment time will range between 1.2 and 2.5 percent, leading to reduction of aggregate trade costs between 1.1 and 2.2 percent. For Belt and Road economies, the change in shipment times and trade costs will range between 1.7 and 3.2 percent and 1.5 and 2.8 percent, respectively. Belt and Road economies located along the corridors where projects are built experience the largest gains. Shipment times along these corridors decline by up to 11.9 percent and trade costs by up to 10.2 percent.
\end{abstract}

JEL Code: F14, F15, R41

Keywords: Transport infrastructure, GIS analysis, shipment times, trade costs

\footnotetext{
${ }^{1}$ The database associated with this paper can be accessed at: https://datacatalog.worldbank.org/dataset/bri-tradecosts-database-wps8614-0.

We thank Alan Deardorff, Michael Ferrantino, Caroline Freund, David Laborde, Mathilde Lebrand, Aaditya Mattoo, Chunlin Zhang, and seminar participants at the World Bank for helpful suggestions and Tristan Reed and Sasha Trubetskoy for their help in gathering information about transport infrastructure linked to the Belt and Road Initiative. Errors are our responsibility only.

Disclaimer: The findings, interpretations, and conclusions expressed in this paper are entirely those of the authors. They do not necessarily represent the views of the International Bank for Reconstruction and Development/World Bank and its affiliated organizations, or those of the Federal Reserve.
} 


\section{Introduction}

The Belt and Road Initiative (BRI) is a development strategy proposed by China that focuses on connectivity and cooperation on a trans-continental scale. It roughly follows and expands the old Silk Road on the land side and complements it with a maritime part to build a series of economic corridors with the goal of boosting trade and stimulating economic growth across Asia, Europe and Eastern Africa. ${ }^{2}$ The range of initiatives and activities that will be part of the BRI is very wide, including policy coordination, infrastructure, trade and investment, financial and people-to-people exchanges. In this paper, we focus on the consequences of transport infrastructures linked with the Belt and Road Initiative and quantify the associated decrease in shipment times and ultimately trade costs. We build two new databases with estimates of trade cost changes across sectors and country-pairs and provide an analysis of the systemic impact that the BRI may have on trade costs for all countries in the world.

The new databases presented in this paper are composed of two sets of data that can be used to address different research questions. The global database contains information based on an analysis of 1,000 cities in 191 countries and 47 sectors. The regional database contains the same variables but focuses on the 71 economies that are part of the Belt and Road Initiative and is computed with a higher degree of granularity. ${ }^{3}$ In particular, the focus on fewer countries allows to include in the analysis a larger number of cities.

In terms of method, we first use a combination of geographical data and network algorithms to compute the reduction in shipping times between all city pairs in our analysis. As a starting point, we use the current network of railways and ports across the world and employ a shortest path algorithm to compute an estimate of the current shipping times between every pair of cities. We use assumptions regarding the average speed for different transportation modes as well as data for the processing time when reaching a port or when crossing borders. From this reference point, we run a series of "improved scenarios", where the transportation network is enriched with all planned infrastructure projects that are linked to the Belt and Road Initiative. We show that by increasing the number of rail and port connections and by improving the speed and processing times for improved rail segments and ports, the Belt and Road Initiative can significantly contribute to decreases in shipping times between a large number of city-pairs in BRI economies as well as in many other countries.

A complex issue is how to deal with the possible switch of transport modes once BRI infrastructure projects are completed. In computing the shipping times post-BRI, we consider two alternative specifications in order to build a lower bound and an upper bound for our estimates. In the lower bound scenario, we

\footnotetext{
2 The Belt and Road Initiative is structured around two main components, (i) the Silk Road Economic Belt (SREB), and (ii) the 21st Century Maritime Silk Road (MSR). More specifically, the "Belt" links China to Central and South Asia and onward to Europe, while the "Road" links China to the nations of South East Asia, the Gulf Countries, East and North Africa, and on to Europe. Those parts are themselves organized around six economic corridors: (1) the China-Mongolia-Russia Economic Corridor; (2) the New Eurasian Land Bridge; (3) the China-Central Asia-West Asia Economic Corridor; (4) the China-Indochina Peninsula Economic Corridor; (5) the China-Pakistan Economic Corridor; and (6) the Bangladesh-China-India-Myanmar Economic Corridor.

${ }^{3}$ There is no official list of countries in the Belt and Road Initiative. For this study, we focused on a list of 71 economies (Annex 1). Countries in the list should be interpreted as economies that are geographically located along the Belt and Road as proposed by China.
} 
prevent mode switching between the pre-BRI and the post-BRI shipping routes so that the decreases in shipping times are solely driven by a denser network of links. Under this assumption, the average decrease in shipping time is 1.2 percent across all country pairs. In the upper bound scenario, we allow for mode switching, so that some trade routes can move from maritime links to rail-based links and hence experience a larger gain in shipping time. In this scenario, the decrease in shipping time at the world level reaches 2.5 percent. Overall, our results underline the importance of network effects in transportation and feature a wide geographical dispersion in the benefits from the BRI. Indeed, our estimated gains are spread across the world, with all countries experiencing a decrease in shipping time with at least one of their partners. $\mathrm{BRI}$ economies experience a decrease in shipment times ranging between 1.7 and 3.2 percent on average.

We then use Hummels and Schaur (2013) sectoral estimates of "value of time" to transform reductions in shipping time into reduction in ad-valorem trade costs. Since Hummels and Schaur's (2013) estimates are very disaggregated (at the HS2 or HS4 level), we need to aggregate them for each country pair using appropriate trade weights. We work with 47 sectors based on the Global Trade Analysis Project (GTAP) categorization and excluding services. Since each of those sectors contains many HS2 or HS4 categories, the composition of trade flows within each GTAP sector differs across country pairs. Hence, we compute the "value of time" for each pair of countries and GTAP sector to reflect the actual composition of each sector within each origin-destination flow.

The results combining our GIS network analysis and the ad-valorem conversion suggest that implementing all BRI transport infrastructure projects will result in a large decrease in trade costs for many countries. For the world, the reduction of aggregate trade costs ranges between 1.1 percent in the lower bound scenario and 2.2 percent in the upper bound scenario. For the BRI economies, the change in trade costs will range between 1.5 and 2.8 percent, under the lower and upper bound scenario respectively. As for shipping times, the gains in trade costs exhibit significant heterogeneity across pairs of countries, with East Asia and Pacific as well as South Asia being the regions with the largest average reductions.

Our paper relates to several strands of literature. First, the importance of time as a trade barrier has been studied extensively in the literature and the heterogenous sensitivity of products to shipment delays has been documented in a number of papers including Hummels (2001), Hummels, Minor, Reisman, and Endean (2007), Djankov, Freund and Pham (2010), Hummels and Schaur (2013) and Baniya (2017). Second, several recent studies have analyzed the trade effects of infrastructure projects either within or across countries (Donaldson (2018); Duranton, Morrow and Turner (2014); Alder (2017)). Third, a subset of this literature also relies on georeferenced data and GIS analysis to assess the trade and the spatial effects of transport infrastructure (e.g. Roberts, Deichmann, Fingleton and Shi (2010); Volpe Martincus, Carballo and Cusolito (2017)). By providing precise estimates of the potential decrease in trade costs expected from the Belt and Road Initiative, our databases are being used as inputs in papers assessing the potential implications of the BRI for trade flows, foreign investment, GDP and welfare (e.g. de Soyres, Mulabdic and Ruta (2018); Baniya, Rocha and Ruta (2018); Maliszewska and van der Mensbrugghe (2018); Chen and Lin (2018); Bird, Lebrand and Venables (2018)).

The paper is organized as follows. Section 2 presents the database on BRI transport projects and the methodology used to measure shipping times. Results of the network analysis are presented in Section 3, while the impact of the BRI on trade costs is analyzed in Section 4. Section 5 presents all variables and descriptive statistics for our two databases. Concluding remarks follow. 


\section{Network analysis: Method and assumptions}

The Belt and Road Initiative covers a large number of transport projects in many countries. The consequences of implementing all those improvements is a priori very hard to forecast: for example, the benefit from building a new segment of rail might depend on the construction or upgrade of a new port at the end of the rail when joining the coast. Furthermore, the optimal route between two cities might depend on the implementation of several projects, which means that one cannot study transport infrastructures independently from one another. The interconnectedness of all elements in the transportation network poses a challenge to any researcher trying to estimate the changes in trade costs that can reasonably be gained from the BRI.

In order to embrace the complexity of network effects while at the same time taking into account all planned BRI transport projects and all countries in the world, our analysis is based on an estimation of shipping times. Specifically, our goal is to develop and implement a structured method to compute the shipping time between all city pairs in the world before the BRI and after the implementation of all identified BRI transport projects. This section presents our methodology and assumptions in detail.

\section{a. Overall method}

As a starting point, we build a network model which takes into account in a precise way the current transportation network and we use it to compute shipment times between all city-pairs using a shortest path algorithm. From this reference point, we run multiple "improved" scenarios that account for the planned infrastructure projects linked to the BRI and we assess the reduction in shipping times resulting from these projects. The list of projects we consider is presented in the supplemental appendix while the associated assumptions for the computation of shipment time is described in the next sub-section.

We carry out the analysis using a GIS software which allows us to precisely map the current transportation network and then to enrich it with the planned infrastructure improvements that can be linked to the BRI. In particular, we use ArcGIS Network Analyst which provides network-based spatial analysis tools for solving complex routing problems. A network solution involves finding the shortest path between two locations, where the length or cost of a path is the total accumulated shipping time computed along the optimal path.

In our analysis, we focus on rail and maritime links, abstracting from road and air connectivity, which allows to simplify the network analysis. Two main reasons justify this approach. First, as discussed in detail below, the large majority of BRI transport projects consist of rail and maritime infrastructure. Second, most international trade travels by sea and, to a smaller extent, by rail. Maritime shipping accounts for $80 \%$ in volume and $70 \%$ in value of global trade (OECD, 2017) and rail is the second transportation mode used, while only a small portion of international trade travels by road and air. GTAP data indicate that for BRI countries the percentage of international shipments by water and land is around $90 \%$. According to shipping data, this fraction is even higher for China (see online appendix). 
The nodes of our network in the global database, which serve as both origin and destination in the analysis, are all cities with population greater than $500,000,{ }^{4}$ as well as the two most populous cities in each country (data permitting). This creates a total of 1,000 cities and includes 34 cities with reported population less than 50,000. In our regional database, we use all cities above 100,000 inhabitants within the BRI countries under consideration, which leads a total of 1,964 cities in 71 economies. The network is solved for each origin-destination pair, with routing determined by shortest time path, adjusting for preference parameters. $^{5}$

The use of a network analysis to quantify shipment times and the impact of new and improved transport infrastructure has benefits and drawbacks. On the plus side, a network analysis can be a useful tool to support modeling of international trade flows. It can enhance the understanding of the impact of changes in infrastructure or other factors on an interconnected system allowing to extract information from spatial data. Specifically, a network analysis allows to obtain realistic measures for the time it takes to go from one location to another taking into account the overall quality and quantity of infrastructure, physical obstacles (e.g. rough terrain) or other barriers (e.g. border delays), and relative performance measures (e.g. processing time at ports or when crossing a border).

As with any modeling exercise, it should be noted that our network is a simplified version of reality and results are affected by the quality of inputs. For example, we do not include some elements that could affect routing, such as rail gauge, freight or passenger lines, service frequency, etc. An additional limitation that needs to be acknowledged comes from the fact that the Belt and Road Initiative includes some efforts that are not easily introduced to the network: improving efficiency of customs, special economic zones, reducing border delays or an improved management of economic corridors. As an extension of our main database, in the supplemental appendix, we present two scenarios where those elements are explicitly taken into account. Finally, our results are driven by a number of assumptions regarding the speed along different path as well as the choice of transportation mode, the processing time when reaching a port and the time it takes to cross a border. We describe those assumptions in detail below.

\section{b. Transport network and BRI-related transport infrastructure projects}

We start with an initial network of links connecting all cities considered in our analysis, and we then add additional links and improved speed corresponding to transport infrastructure projects that are linked to the Belt and Road Initiative. Our initial network comes from Delorme Atlas of the Earth (DAE), 2015 release. For our analysis, maritime features were generated separately for the Pacific, Atlantic and Indian Oceans, and for the Caribbean Basin and Seas of Indonesia. To simulate plausible trans-oceanic shipping routes, great-circle $\operatorname{arcs}^{6}$ were generated from port locations along the boundary of Exclusive Economic Zones. Within the Caribbean Basin, around Indonesia, and near land, connectivity to major ports was manually digitized using a map of Global Shipping Routes (ESRI, CIA, 2012).

\footnotetext{
${ }^{4}$ Population sources are https://www.citypopulation.de/world/Agglomerations.html and http://data.un.org/Data.aspx?d=POP\&f=tableCode\%3A240

${ }^{5}$ To "attach" cities to elements of the transportation network (a rail segment or a port), a fuzzy tolerance of $10 \mathrm{~km}$ was used. As a result, any city located more than $10 \mathrm{~km}$ away from any network element is left as unconnected and de facto excluded from the results.

${ }^{6}$ Shortest distance between two points on the surface of a sphere, measured along the surface of the sphere.
} 
When building our estimates of shipping time reductions that can be associated with the BRI, we need to enrich the current transportation network with planned projects. Compiling a list of transport infrastructure projects associated with the BRI is a delicate task since there is no one criterion that could be used to define what is or is not part of the initiative. In particular, there might be projects financed by loans from China that might not necessarily fall under the BRI, and there might be projects with nonChinese funding that are still considered in some sources as being part of the BRI.

We start from the list of infrastructure projects developed by Reed and Trubetskoy (2018) and which considers projects respecting all three following criteria:

1. The project is explicitly mentioned in one of the following sources as being part of BRI: either document issued by a government (including government press agencies), or article in a major academic journal or global news source or a quote by a government official in a reputable news source.

2. The project is at least in the planning phase.

3. The project impacts travel between two cities of at least 300,000 inhabitants.

These criteria present the advantage of restricting our list to projects that have been indeed related to the $\mathrm{BRI}$ and to exclude some projects for which feasibility might be in question. For example, condition 2 excludes the Moscow-Beijing high speed rail or the Bering Strait connection, which were proposed but have no real plans. Moreover, condition 3 excludes small road projects in Cambodia that are clearly not along any shortest path linking major cities.

We simplify the list of projects from Reed and Trubetskoy (2018) and keep only the rail and maritime elements. Then, to ensure consistency with the information on the ground, we validate it with the help of World Bank country teams. As a result, the exact list of all projects used in the analysis and sources can be found in the supplemental appendix. We then geo-localize each of these projects in our map and generate links with the current rail lines, ports and maritime links, which creates a denser transportation network on which we can run our shortest path algorithm.

\section{c. Working assumptions}

The multimodal network used in this analysis was constructed by merging two types of features: maritime and rail. ${ }^{7}$ These features are largely non-overlapping and separated in space. The shortest path algorithm is used to find the shortest routing (in terms of shipping time) between any city-pair in our network and taking into account all possible ways to link the origin city to the destination city. In order to find such optimal route, each network element is associated with a time cost which is accumulated along the route to sum up to the total shipping time. Time is then calculated as the segment length divided by speed, where the speed of distinctive features is presented in Table 1.

\footnotetext{
${ }^{7}$ On top of rail and maritime networks, there are a few particular cases where we added road segments for cities characterized by extremely low or inexistent rail connectivity. This happened in exactly 8 cases for the following cities: Osh (Kyrgyzstan), Kabul (Afghanistan), Thimpu (Bhutan), Kigali (Rwanda), Guatemala City \& Mixco (Guatemala), San Salvador (El Salvador), León \& Managua (Nicaragua) and Belmopan (Belize). In those cases, we used a speed of $25 \mathrm{~km} / \mathrm{h}$ for the associated road segment.
} 
Table 1: Speed assumption for different transport modes

\begin{tabular}{|c|c|c|}
\hline Description & Pre-BRI & Post-BRI \\
\hline Maritime & $25 \mathrm{~km} / \mathrm{h}$ & $25 \mathrm{~km} / \mathrm{h}$ \\
\hline Upgraded rail & $50 \mathrm{~km} / \mathrm{h}$ & $75 \mathrm{~km} / \mathrm{h}$ \\
\hline New rail & - & $75 \mathrm{~km} / \mathrm{h}$ \\
\hline
\end{tabular}

The choice of transportation mode is difficult to model and follows different logics and trade-offs which are specific to the sector under consideration. It depends on the different elements that affect shipping costs such as the bulkiness of the good, subsidies, oil price, market structure and many others that cannot be modeled in a sensible way in our analysis. To account for the very high share of maritime shipping in international trade, we use a network preference to produce a maritime alternative where land connectivity exists. Within the optimal path algorithm, this preference is implemented in the following way: for any city pair that has access to both a maritime and a rail link, the algorithm selects the maritime option whenever the shipping time is lower than four times the shipping time incurred using the rail link. While such a criterion can be seen as a strong simplification of the actual trade-off faced by many logistic companies, the imposition of such a preference for maritime links allows us to have a representation of the world that is very much in line with other data sources in terms of both modal shares and total shipping times at the city-pair level. For example, in our pre-BRI scenario with the global database, maritime transportation represents a total of $82.3 \%$ of all trade routes. In the following sub-section, we explain in detail how we deal with the possibility of mode switching once all BRI projects are implemented.

On top of the time cost computed along the network elements, we account for processing times when a shipment is reaching / leaving ports, based on the estimates in Slack, Comtois, Wiegmans and Witte (2018). In their paper, Slack et al (2018) use data from Lloyds Intelligence Unit and base their estimates on a sample of 17,024 vessels in 2013. In our network, we use their regional averages reported in Table 2. In the context of our analysis, these processing times correspond to a "penalty" incurred when reaching a port, either from the land and from the sea, and correspond to the time it takes to load or unload the goods. In the improved scenario, when a project involves building a new port or upgrading an old port, we assume that the associated "processing time" decreases according to the following rule:

Improved Port Delay $=$ Max (0.5*Baseline port Delay, Lowest Worldwide Processing Time)

This rule allows us to account for a proportional decrease in port delay of 50 percent with a limit that no port can be more efficient than the worldwide lowest estimate of 17.2 hours. 


\begin{tabular}{|l|c|}
\multicolumn{1}{|c|}{ Region } & $\begin{array}{c}\text { Mean Ships Time In Port } \\
\text { (hours) }\end{array}$ \\
\hline Central and South America & 23.5 \\
\hline South and South-East Asia & 26.5 \\
\hline East and North Asia & 17.2 \\
\hline Gulf and Red Sea & 26.8 \\
\hline Mediterranean & 20.3 \\
\hline Northern Europe & 29.5 \\
\hline North America - East Coast & 21.1 \\
\hline North America - West Coast & 46.2 \\
\hline South Africa & 64.6 \\
\hline
\end{tabular}

Finally, processing time when crossing an international border is also an important part of overall shipment time for international trade. To account for border delays in our computations, we include importing and exporting time from the "trading across borders" section in the World Bank's Doing Business Database. ${ }^{8}$ The data is available for each country considered in our analysis and Table 3 presents the average values aggregated by region. To get bilateral values for border delays for each directed country-pair, we compute the total border delay as the sum of importing and exporting time for each origin and destination respectively. Whenever a border is crossed along the optimal route, the "border penalty" is incurred.

Table 3: Export and Import processing time at the border (from the Doing Business Database)

\begin{tabular}{|l|c|c|}
\multicolumn{1}{|c|}{ Region } & $\begin{array}{c}\text { Time to export: Border compliance } \\
\text { (hours) }\end{array}$ & $\begin{array}{c}\text { Time to import: Border compliance } \\
\text { (hours) }\end{array}$ \\
\hline East Asia \& Pacific & 55.9 & 70.5 \\
\hline Europe \& Central Asia & 28 & 25.9 \\
\hline Latin America \& Caribbean & 62.5 & 64.4 \\
\hline Middle East \& North Africa & 62.6 & 112.3 \\
\hline South Asia & 59.4 & 113.8 \\
\hline Sub-Saharan Africa & 100.1 & 136.4 \\
\hline
\end{tabular}

Finally, we offer external validation of our results in the supplemental appendix and show that our shipping time estimates before the BRI are in line with other sources of information regarding shipping time.

\footnotetext{
${ }^{8}$ For any border, we use the data on "Border Compliance" and the total delay is assumed to be the sum of export time from the exporting country and the import time from the importing country. We do not include documentary compliance as it does not relate to travel time. All data are available at:

http://www.doingbusiness.org/data/exploretopics/trading-across-borders
} 


\section{Effects of the Belt and Road Initiative on shipping times}

In this section, we present the results on shipment times from the network analysis before and after the Belt and Road Initiative. We first construct two scenarios: a lower bound scenario, where exporters cannot switch mode of transport after the BRI infrastructure projects are completed, and an upper bound scenario where the transportation mode can change. Then we proceed to estimate the effects of the BRI on shipping times under these two scenarios. ${ }^{9}$

\section{a. The lower bound scenario}

Recognizing that choices of transportation mode do not only take into account shipment time but also shipment costs and other considerations, we build our main estimates of reduction in shipment time by avoiding large changes in transport mode before and after the BRI. These are conservative estimates as the new BRI infrastructure might actually induce some firms to substitute maritime link in favor of rail links which might be more expensive but also significantly faster. By not considering these changes, the estimates should be interpreted as the minimum gains in terms of shipping time that can be achieved by taking advantage of all new and upgraded transport links but without any change in the transportation mode.

Taking the "pre-BRI" results from the previous section as a starting point, we build a first "post-BRI" scenario where the shares of maritime and rail transportation modes would not exhibit significant change for each city-pair. ${ }^{10}$ To do so, we use a two-steps procedure. We provide here an intuitive description of our method and give a more detailed explanation in the annex.

We proceed in two steps. First, we run a network analysis with all BRI transport projects taken into account and find the optimal shipping route between all city-pairs, keeping our maritime preference as in the preBRI computation. Second, for each origin-destination, we compute the share of maritime and rail in the optimal path and compare them to the modal shares from the pre-BRI scenario. If the optimal route after the BRI features a change in the modal share lower than $5 \%$, we keep the result as is since there is no major shift in transportation mode. If, instead, the optimal route features a modal switch above $5 \%$, we run additional scenarios and change the preference for maritime links until we find a shipping route post-BRI that keeps the transportation mode unchanged.

The procedure described above allows us to obtain results at the city-pair level where before and after BRI travel time can be compared in a sensible manner. It should be emphasized that this lower bound scenario indeed corresponds to a conservative estimate since exporters benefit from an improved network but they

\footnotetext{
${ }^{9}$ One difficulty of such a network analysis is the association of each city with an "entry point" in the transportation network - usually referred to as "snapping". Because cities are never exactly located on the network, we need to specify a snapping tolerance when performing this step. Since we compare two scenarios (before and after the BRI), we also need to make sure each city is associated with the same snapping unless there is a new network element in their surroundings. To ensure we do not have inconsistencies between scenarios, we compare the snapping and manually exclude all cities featuring difference between scenarios. The number of cities quoted in the paper $(1,000$ in the global database and 1,964 in the regional database) reflects the cities selected through this procedure and which are actually used in our analysis.

${ }^{10}$ In the supplemental appendix, we also show that the network analysis results in the pre-BRI scenario are in line with other data sources both in terms of city-pair shipping times and in terms of aggregate modal shares.
} 
cannot take advantage of those improvements to change their transportation mode. Figure 1 below shows an example of route before and after the BRI where there is no significant mode switch - and which therefore are part of the lower bound analysis. The shipping route between Beijing and Dushanbe goes through rail links both before and after the implementation of BRI transport projects. It is apparent from the map that the construction of new rails shortens the route between those cities. In addition, the route contains "upgraded" parts (not shown in the figure) where the rails are not new but the speed along some segments is enhanced as part of the BRI.

Figure 1: Shipping route before and after the BRI between Beijing and Dushanbe - Lower Bound analysis.

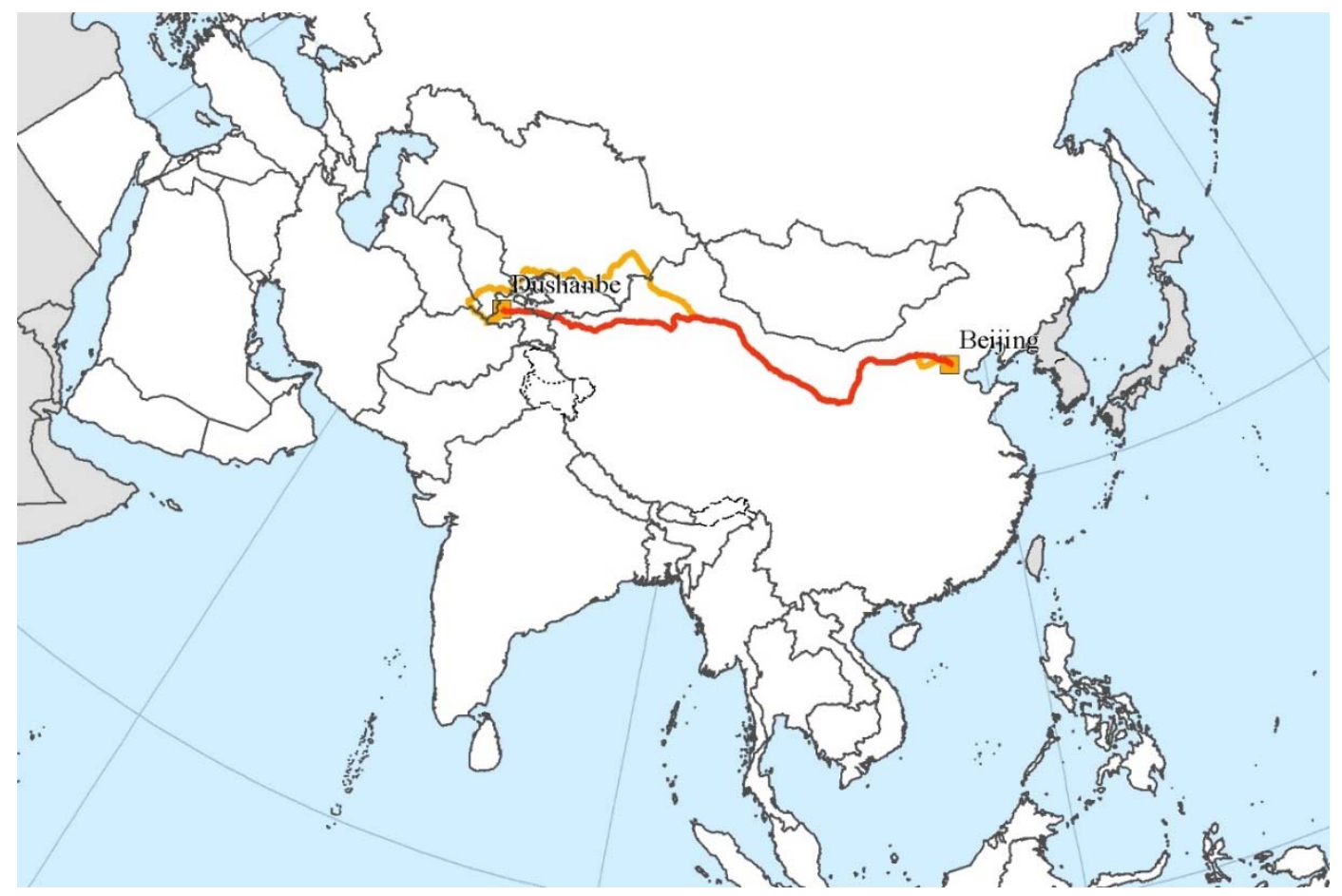

Note: The yellow line is the "pre-BRI" route while the red line corresponds to the "post-BRI" route.

\section{b. The upper bound scenario}

As an alternative to our conservative estimates, we now turn to the construction of an upper bound scenario of the changes in shipment time that can be achieved through the Belt and Road Initiative. In building the upper bound scenario, our goal is to allow changes in transportation mode once the BRI projects are taken into account so that new and upgraded rail links might divert some routes away from long maritime routes towards shorter rail connections.

One difficulty of our method based on a shortest path algorithm with a preference for maritime links is that if we simply remove the preference for maritime links in the post-BRI computation we might observe city-pairs using shorter rail links even in the absence of any BRI changes. In other words, if we just remove the constraint of maritime preference, some changes in optimal route and transport mode will happen independently on whether there is a BRI project or not. It would therefore be misleading to input those changes as BRI improvements. 
We deal with this issue in the following way: first, we compare the modal shares in the pre-BRI setup with and without maritime preference. This allows us to identify city-pairs where the modal switch from maritime to rail occurs even without any network improvements. For such city-pairs, we keep the result from our lower bound scenario, since we cannot say that the modal choice change is due to BRI projects. We are then left with city-pairs that did not experience a switch in transportation mode when we remove the maritime constraint: for those links, we run a post-BRI scenario without preference for maritime links and keep the results unchanged in the case the optimal route after the BRI involves a higher share of rails compared to the pre-BRI scenario.

Figure 2: Shipping route before and after the BRI between Beijing and Tehran - Upper Bound analysis.

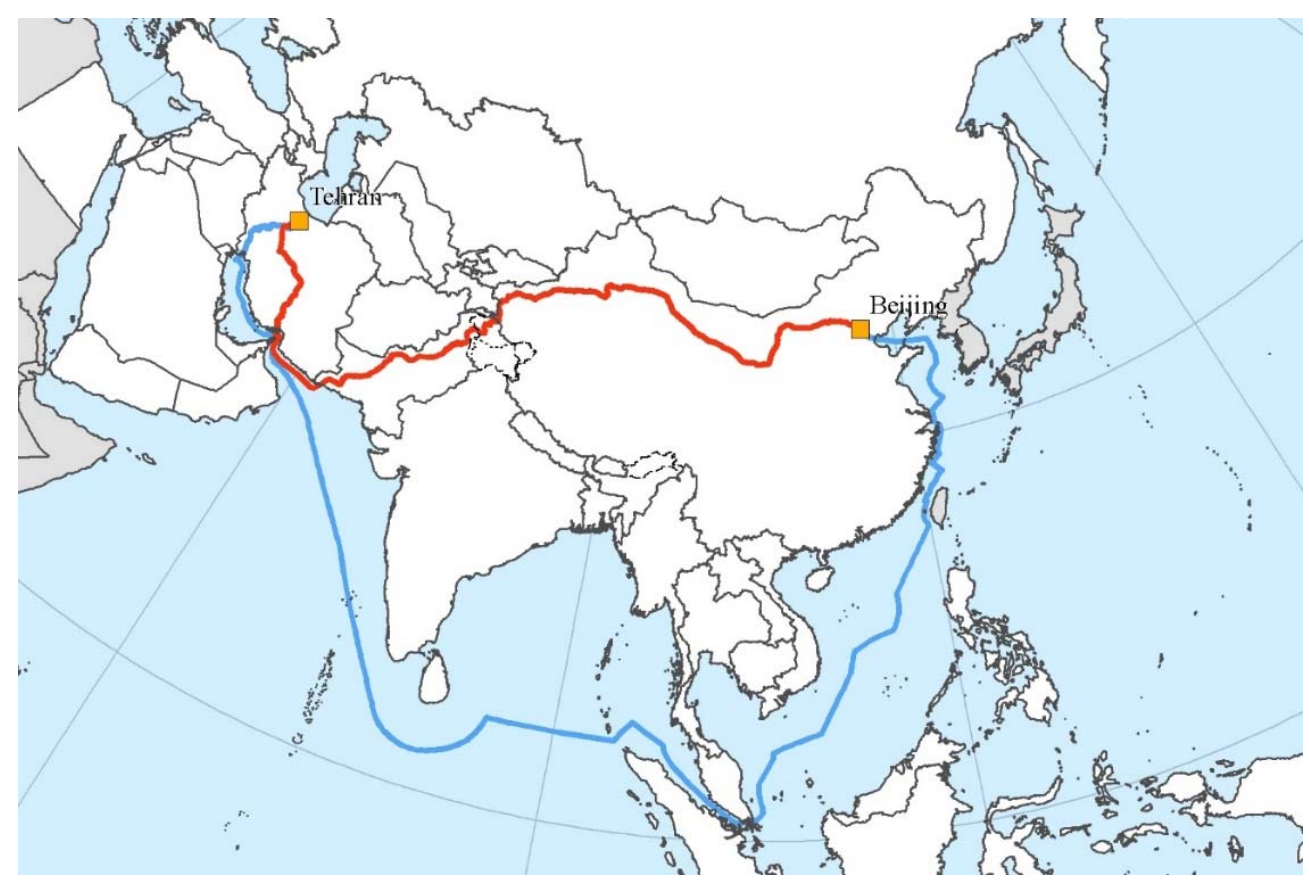

Note: The light blue line is the "pre-BRI" route while the red line corresponds to the "post-BRI" route.

Figure 2 presents an example of such a case: the link between Beijing and Tehran experiences a dramatic change in the transportation mode when we compare before and after the BRI. In our upper bound scenario, we keep such a large gain in shipment time because we know such a switch could indeed be triggered by BRI-related network improvements.

\section{c. Results from the global and regional databases}

Based on the method detailed above, we estimate reductions in shipment time between all the pairs of cities considered in our analysis. To aggregate all values at the country-pair level, we take a populationweighted average of the city-pair reductions to compute country-pair level values. More precisely, we first compute the total population of each city-pair by summing the population of origin and destination cities, and then use this total population as weights in the country-pair aggregation. We do this exercise for our global database -using a total of 1,000 cities in 191 countries- and for the regional database -covering 1,964 
cities and 71 economies. We present first the results of the global database and then discuss the main differences with the regional database.

Our first step is to look at the changes in the average shipping time before and after the BRI for the world. Before the BRI, the average shipping time for all country-pairs is 22.9 days. This declines to 22.6 and 22.3 days in the lower and upper bound scenarios, respectively. The proportional reduction in shipping time ranges between 1.2 and 2.5 percent. In other words, the BRI is expected to contribute to a decrease in shipping times of 7 to 15 hours across all country-pairs in the world. It is important to note that this average is taken with respect to all possible country pairs in the world, some of which are not or very little affected at all by the BRI.

To have a better sense of the consequences of the BRI we aggregate the results across pairs of regions. ${ }^{11}$ Looking at the figures in table 4, one can notice several interesting patterns. First, as expected, the East Asia and Pacific region is experiencing the largest decrease in shipping times vis-à-vis all the other regions (first column in table 4). The highest gains are between the East Asia and Pacific and South Asia, with the average gains reaching 4.67 percent when aggregating across all country pairs. Second, while not all pairs of regions are expected to have gains (there is no change in shipping time between North America and the Latin America), every single region will benefit with at least some of their partners. As an example, it is worth noting that the Latin America and Caribbean region is expected to decrease the shipping time by 1.15 percent with countries in the South Asia region.

At a more disaggregated level, the results also feature significant heterogeneity when looking across country-pairs. For example, among the top ten countries experiencing the largest decrease in shipping time with China, there are countries in Asia (Kirghizstan, Bangladesh, Malaysia) but also countries in Africa (Tanzania, Mauritius, Kenya). ${ }^{12}$ These results show why it is important to use a network approach in order to understand the interconnections of all planned infrastructures: the gains in Kenya are the results of the infrastructure in both Kenya and in several countries in Asia. The benefits from the Lamu port and LAPSSET rail corridor in Kenya are magnified by the rails in Myanmar, Thailand and Pakistan as well as the port projects in Kyaukpyu (Myanmar) and Gwadar (Pakistan).

Another interesting feature that naturally comes out of our network approach is the global and systemic impact of localized infrastructure projects. Upon the implementation of a new/upgraded port or rail, shipping time decreases for all routes going through the new network element. This means, for example, that the BRI will also reduce shipping times - and ultimately trade costs - not only between BRI countries, but also potentially between country-pairs that are not part of the Initiative. For instance, Tanzania's Bagamoyo port is expected to benefit not only Tanzania but several other countries in the region. As a result, when all BRI transport projects are implemented, our analysis shows that shipping time between Australia and Rwanda is expected to decrease by 0.5 percent. Similarly, the improvement of Djibouti's port will contribute to a decrease in shipping time between Australia and Ethiopia of 1.2 percent.

\footnotetext{
${ }^{11}$ Regions are defined using the World Bank classification.

${ }^{12}$ See the supplemental appendix for a table presenting country-specific results.
} 
Table 4: Proportional decrease in shipment time, aggregated by regions - Lower Bound.

\begin{tabular}{|c|c|c|c|c|c|c|c|}
\hline & $\begin{array}{l}\text { East Asia \& } \\
\text { Pacific }\end{array}$ & $\begin{array}{c}\text { Europe \& } \\
\text { Central Asia }\end{array}$ & $\begin{array}{c}\text { Latin America \& } \\
\text { Caribbean }\end{array}$ & $\begin{array}{c}\text { Middle East \& } \\
\text { North Africa }\end{array}$ & $\begin{array}{c}\text { North } \\
\text { America }\end{array}$ & South Asia & $\begin{array}{c}\text { Sub-Saharan } \\
\text { Africa }\end{array}$ \\
\hline $\begin{array}{c}\text { East Asia \& } \\
\text { Pacific }\end{array}$ & 2.01 & & & & & & \\
\hline $\begin{array}{c}\text { Europe \& } \\
\text { Central Asia }\end{array}$ & 2.70 & 1.15 & & & & & \\
\hline $\begin{array}{l}\text { Latin America } \\
\& \text { Caribbean }\end{array}$ & 0.71 & 0.75 & 0.00 & & & & \\
\hline $\begin{array}{l}\text { Middle East \& } \\
\text { North Africa }\end{array}$ & 2.99 & 0.38 & 0.05 & 0.14 & & & \\
\hline North America & 1.06 & 0.74 & 0.00 & 0.18 & 0.00 & & \\
\hline South Asia & 4.67 & 0.88 & 1.15 & 0.70 & 1.49 & 3.59 & \\
\hline $\begin{array}{l}\text { Sub-Saharan } \\
\text { Africa }\end{array}$ & 2.54 & 1.06 & 0.55 & 0.91 & 0.47 & 2.59 & 0.97 \\
\hline
\end{tabular}

Note: Results are from the Lower Bound analysis and averaged over all country-pairs in each region-pair.

In general, the results highlight the systemic impact of the transport projects in reducing shipping times. While some country-pairs are not expected to experience changes in shipping time, the benefits from all those investments will spread far beyond the countries formally participating in the initiative. Hence, only a holistic network approach, taking into account the details of both the current network of infrastructure and the planned projects, can account for all interconnections and spillover effects that can be expected from the BRI.

Figure 3: Average decrease of shipping time per country - Upper Bound.

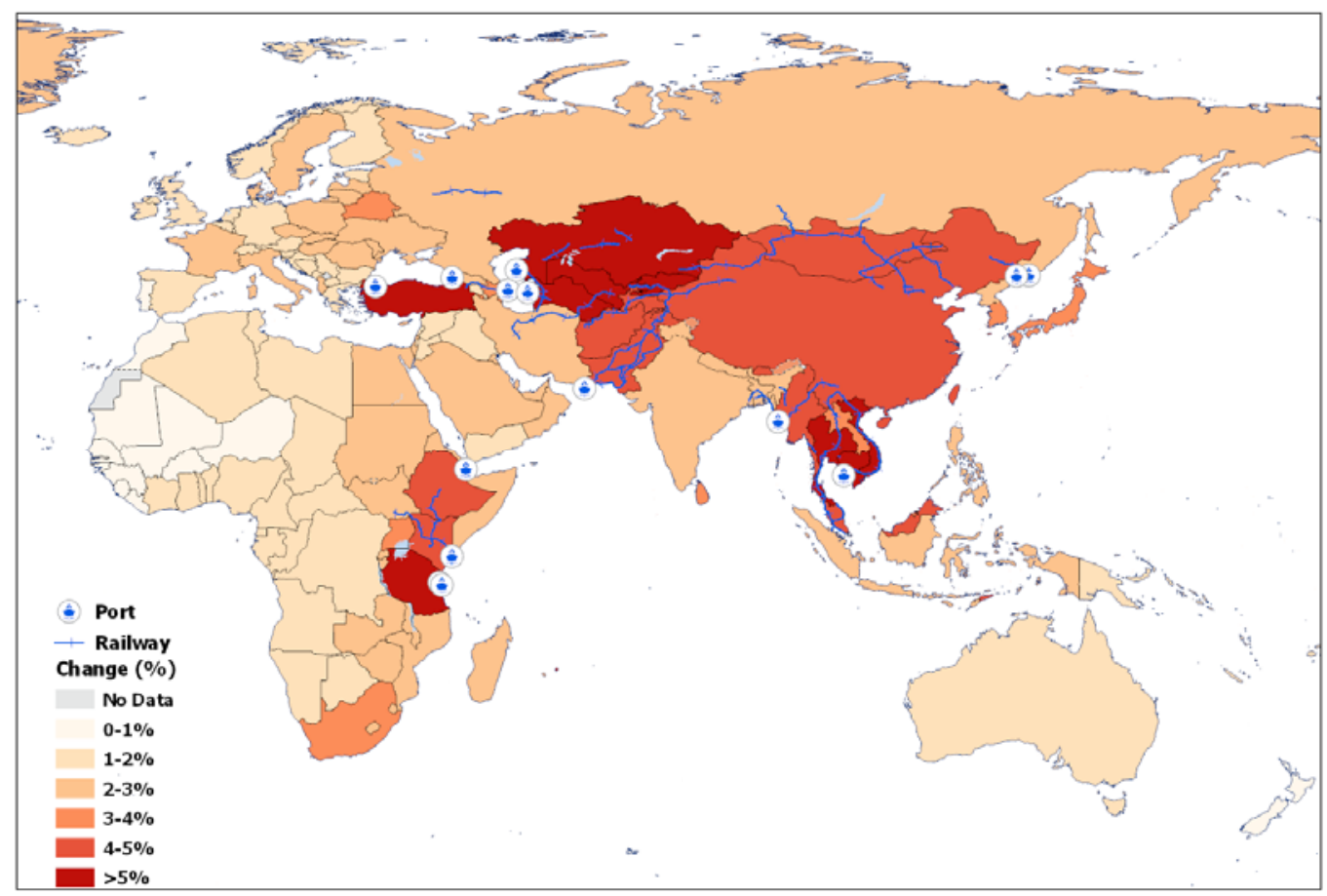

Note: For each country, the aggregate proportional decrease is computed as the average of proportional shipping time decrease with all other countries in the world. Results using our "Lower Bound" estimates are presented in the supplemental appendix. 
The main conclusions from the analysis on the impact of the BRI on shipping times across countries based on the global database are also valid for the regional database. Specifically, the proportional decrease in shipping times after the BRI interventions within the BRI region for the lower and upper bound scenarios is equal to 2.86 percent and 4.45 percent on average for the regional database, compared to 2.37 percent and 3.96 percent for the global database (see Table 5).

Table 5: Improvements in shipment times post-BRI, comparative statistics for regional and global databases on BRI sub-sample of countries.

\begin{tabular}{|c|c|c|c|c|c|c|c|c|}
\hline & \multicolumn{2}{|c}{ Min } & \multicolumn{2}{c}{ Max } & \multicolumn{3}{c|}{ Mean } & Std.Dev. \\
\hline $\begin{array}{c}\text { \% decrease in } \\
\text { trading times - } \\
\text { Lower Bound }\end{array}$ & 0.00 & 0.00 & 79.29 & 61.52 & 2.86 & 2.37 & 4.93 & 4.30 \\
\hline $\begin{array}{c}\text { \% decrease in } \\
\text { trading times - } \\
\text { Upper Bound }\end{array}$ & 0.00 & 0.00 & 79.29 & 65.16 & 4.45 & 3.96 & 6.03 & 5.42 \\
\hline
\end{tabular}

\section{Effects of the Belt and Road Initiative on trade costs}

Trade barriers between two countries can take many different forms, including tariffs, quotas and various forms of non-tariff measures such as import licensing or technical standards. Shipment time can also be a form of trade barrier. As customers and firms value accessing goods in a timely manner, any delay in serving different markets might result in a reduction of associated trade flows. Hence, reducing the time it takes to ship and process goods between two countries, either through improvement in infrastructure and shipping routes or through an increase in the efficiency of the clearing process at the border, is likely to reduce trade costs and positively impact the quantity being actually traded.

In this section, we study how the changes in shipment times associated to the Belt and Road Initiative that we have identified in Section 3 translate in changes into trade costs. The analysis will be applied to the global database only, as the main results are valid when considering trading times across countries from the regional database.

A difficulty in this exercise is that the sensitivity of trade flows to shipment time strongly depends on the characteristics of the product considered. In other words, the "value of time" is not equal across industries. Among many sector-specific characteristics governing the impact of time on trade, one can cite the rate of depreciation, storability, seasonality, demand uncertainty or substitutability with domestic products. All those traits influence the elasticity of shipment time to trade flows and it is important to take into account this heterogeneity across sectors.

In the rest of the section, we first discuss the methodology used to transform shipment times into trade costs, then we present the results for the global database.

\section{a. From shipment times to trade costs}

To transform the shipment times from our network analysis into trade costs, we use the seminal work of Hummels and Schaur (2013). This paper provides estimates for the ad-valorem value of a shipment day for 
many sectors, at both four-digit and two-digit levels of disaggregation in the Harmonized System (HS). Recognizing the fact that air cargo is many times more expensive than maritime transport but arrives in destination markets much faster, Hummels and Schaur (2013) use U.S. imports data and detailed information on the premium paid for air shipping and in time lags for ocean transit to identify consumers' valuation of time. To our knowledge, these results constitute the most comprehensive and detailed estimates of value of time at the sectoral level, providing rich heterogeneity and overcoming several endogeneity issues faced by previous work.

In order to construct new data for the ad-valorem "value of time" in GTAP, we must aggregate the estimates at HS-levels from Hummels and Schaur (2013) into GTAP sectors. To perform such aggregation, it must be noted that GTAP sectors are aggregates of many HS categories which are represented with different weights for different country-pairs. As a result, a given GTAP sector should not necessarily be associated with the same "value of time" when we consider different origin and destination countries. We provide more details on the procedure in the supplemental appendix.

We create "value of time" for each GTAP sector and origin-destination pairs that contain at least one HS category that is traded. We then build the ad-valorem time barrier by simply multiplying the shipment time (computed using the network analysis described in Section 3) and the value of time aggregated from HS2 estimates. It is important to keep in mind that for a given shipment time, the ad-valorem time barriers feature sectoral heterogeneity: some sectors are highly time sensitive (for example perishable products) while others are not.

The last step is to calculate the total trade costs. Overall, the time barrier associated with the shipment between two cities is only a fraction of trade costs, which also contains the actual transportation cost as well as the tariffs and other monetary charges that can be applied between respective countries. In the previous section, we focused our analysis on the decrease in trade barriers that can be achieved from a reduction in shipping time and estimated associated decrease in ad-valorem costs. We now need to account for the fact that trade costs encompassing these other elements. In particular, we assume that total trade costs are defined as follows:

\section{Trade Cost $=$ tariff + transport + time cost}

Assuming that both tariff and transportation costs are unchanged, we now compute the decrease in total trade costs that can be expected from the sheer decrease in shipping time and the value of time computed above.

We use data from the latest release of the GTAP database, version 10. One of the main advantages of the GTAP database is the ability to use data related to both tariffs and transport costs at the sectoral level. The complete database contains a total of 57 sectors. In our analysis, we focus on the 47 good sectors and do not consider the remaining 10 service sectors as the value of time and the economic determinants of trade costs for services are very different and outside of the scope of this paper.

One of the caveats of using GTAP, however, is the geographical aggregation is less precise than our previous shipping time analysis. The data contain a total of 140 "regions" and an aggregated rest of the world. While this aggregation means that we are decreasing the geographical granularity of our results, it enables us to build trade costs estimates in a consistent way for a large number of countries and sectors. 


\section{b. Results}

We now present the key results of the impact of BRI related transport projects on trade costs based on the global database. Compared to the figures presented in Section 3, which related to changes in shipping time only, the results presented in this section feature two main differences. First, because trade barriers are not only composed of the time element but also the actual logistical costs and tariffs which we assumed to be unaffected by the BRI, the decrease in trade costs are lower than the decrease in shipping time. Second, while results presented in Section 3 were inherently symmetric across country-pairs, the reductions in trade costs are not symmetric. This is due to the differences in the basket of goods traded within country pairs. If, for example, country A exports mostly time sensitive goods to country B, but imports only time insensitive goods, then a reduction in shipping times will induce a larger decrease in export costs than in import costs for country $A$ and vice versa for country $B$.

Table 6 gives a first overview of our results for both our lower bound and upper bound scenarios. The decrease in trade costs associated with the BRI features a lot of geographical and sectoral heterogeneity. On average, the decline in trade costs associated to BRI projects ranges between 1.05 and 2.19 percent. For some country-pairs this decline is zero, while the maximum change ranges between 61.52 and 65.16 percent. ${ }^{13}$

Table 6: Percentage decrease in trade costs due to the BRI

\begin{tabular}{|c|c|c|c|c|}
\hline & Min & Max & Mean & Std Dev \\
\hline & \multicolumn{4}{|c|}{ World } \\
\hline$\%$ decrease in trade cost - Lower Bound & $0.0 \%$ & $61.52 \%$ & $1.05 \%$ & $2.43 \%$ \\
\hline \multirow[t]{2}{*}{$\%$ decrease in trade cost - Upper Bound } & $0.0 \%$ & $65.16 \%$ & $2.19 \%$ & $3.40 \%$ \\
\hline & \multicolumn{4}{|c|}{ BRI Countries } \\
\hline$\%$ decrease in trade cost - Lower Bound & $0.0 \%$ & $61.52 \%$ & $1.50 \%$ & $3.07 \%$ \\
\hline$\%$ decrease in trade cost - Upper Bound & $0.0 \%$ & $65.16 \%$ & $2.81 \%$ & $4.18 \%$ \\
\hline
\end{tabular}

Table 7 presents the non-symmetric matrix of trade cost changes by region-pair. The results display a similar pattern to the one previously discussed for the shipping time: East Asia and Pacific has the largest gains, followed by South Asia. Some pairs of regions experience no or small changes in trade costs, but all regions have significant gains with at least one of their trading partners. The systemic nature of the Belt and Road Initiative is apparent from the results. First, gains are not limited to the BRI economies or to country-pairs involving at least one BRI economy. For example, averaging across sectors, the decrease in trade costs between Australia and Kirghizstan amounts to 11.1 percent, among the top 2 percent of all

\footnotetext{
${ }^{13}$ In the supplemental appendix, we also provide results focusing on the decrease in "time barrier", which is only one element in total trade costs. Since we make the conservative assumption that only "time barrier" is directly affected by the BRI, reduction in total trade costs is systematically lower than reduction in the "time barrier".
} 
country-pair gains. Trade costs between these two countries are expected to decrease from the BRI especially from the new railways and ports in Pakistan.

Second, the largest decrease in trade costs are not captured by the countries with the largest amount of transport projects. With more than 2,500km of new rail and more than $1,000 \mathrm{~km}$ or upgraded rail, Mongolia is among the countries with the highest investment. When computing the proportional decrease in trade costs with all its partners weighted by import flows (which could be interpreted as the average decrease in import costs for the country), Mongolia experiences a decrease of only 3.22 percent. The same computation for Kenya reveals a decrease in import cost of more than 4.65 percent even though the country is expected to build $1,800 \mathrm{~km}$ of new rail and a new port.

Table 7: Proportional decrease in trade costs, aggregated by regions.

\begin{tabular}{|c|c|c|c|c|c|c|c|}
\hline & $\begin{array}{c}\text { East Asia \& } \\
\text { Pacific }\end{array}$ & $\begin{array}{c}\text { Europe \& } \\
\text { Central Asia }\end{array}$ & $\begin{array}{l}\text { Latin America } \\
\& \text { Caribbean }\end{array}$ & $\begin{array}{c}\text { Middle East \& } \\
\text { North Africa }\end{array}$ & $\begin{array}{c}\text { North } \\
\text { America }\end{array}$ & South Asia & $\begin{array}{c}\text { Sub-Saharan } \\
\text { Africa }\end{array}$ \\
\hline $\begin{array}{c}\text { East Asia \& } \\
\text { Pacific }\end{array}$ & 1.46 & 2.42 & 0.64 & 2.50 & 0.96 & 3.55 & 2.19 \\
\hline $\begin{array}{c}\text { Europe \& } \\
\text { Central Asia }\end{array}$ & 2.39 & 0.91 & 0.72 & 0.32 & 0.70 & 0.74 & 0.95 \\
\hline $\begin{array}{l}\text { Latin America } \\
\& \text { Caribbean }\end{array}$ & 0.65 & 0.71 & 0.00 & 0.04 & 0.00 & 1.08 & 0.51 \\
\hline $\begin{array}{l}\text { Middle East \& } \\
\text { North Africa }\end{array}$ & 2.69 & 0.31 & 0.04 & 0.11 & 0.17 & 0.56 & 0.79 \\
\hline $\begin{array}{c}\text { North } \\
\text { America }\end{array}$ & 0.99 & 0.66 & 0.00 & 0.15 & 0.00 & 1.21 & 0.41 \\
\hline South Asia & 3.84 & 0.81 & 1.06 & 0.57 & 1.32 & 3.17 & 2.30 \\
\hline $\begin{array}{c}\text { Sub-Saharan } \\
\text { Africa }\end{array}$ & 2.40 & 1.03 & 0.53 & 0.85 & 0.45 & 2.44 & 0.86 \\
\hline
\end{tabular}

Note: Results are from the Lower Bound analysis and averaged over all country-pairs in each region-pair.

The unit of observation in our results is at the origin-destination-sector level. ${ }^{14}$ In the supplemental appendix, we also show an analysis where we aggregate the observation for each country to provide an overview of the results. Naturally, there are different ways to aggregate the results at the country level. For example, trade costs are expected to decrease by 6.1 percent between Cambodia and Denmark, which is very significant. But what is the meaning of such a decrease for a firm in Cambodia that does not source any input from Denmark and/or does not sell any good to Denmark? One possible aggregation scheme consists of weighting all destinations by import or export flows and hence gain some insight regarding the potential gain for a global buyer or seller in each country. Focusing on the upper bound results, Error! Reference source not found. presents such an aggregation and show the gains weighted by import flows, so that the results can be interpreted through the lenses of a firm that sources its inputs from abroad.

\footnotetext{
${ }^{14}$ The database contains a variety of useful information and input for researchers such as ad-valorem equivalents of a shipment day at the sector level.
} 
An important caveat to bear in mind is that aggregating all destinations using current trade flows (either imports or exports) as weights might give a biased view of the results. Indeed, current trade weights only provide a static view of the world and do not account for the dynamic impact of the BRI. By reducing trade costs differentially across all country pairs, the BRI will trigger a reallocation of comparative advantages across countries in a complex way and it will change the share of every trading partner in each country's aggregate imports and exports basket. ${ }^{15}$

Figure 4: Average decrease of trade costs per country - Upper Bound.

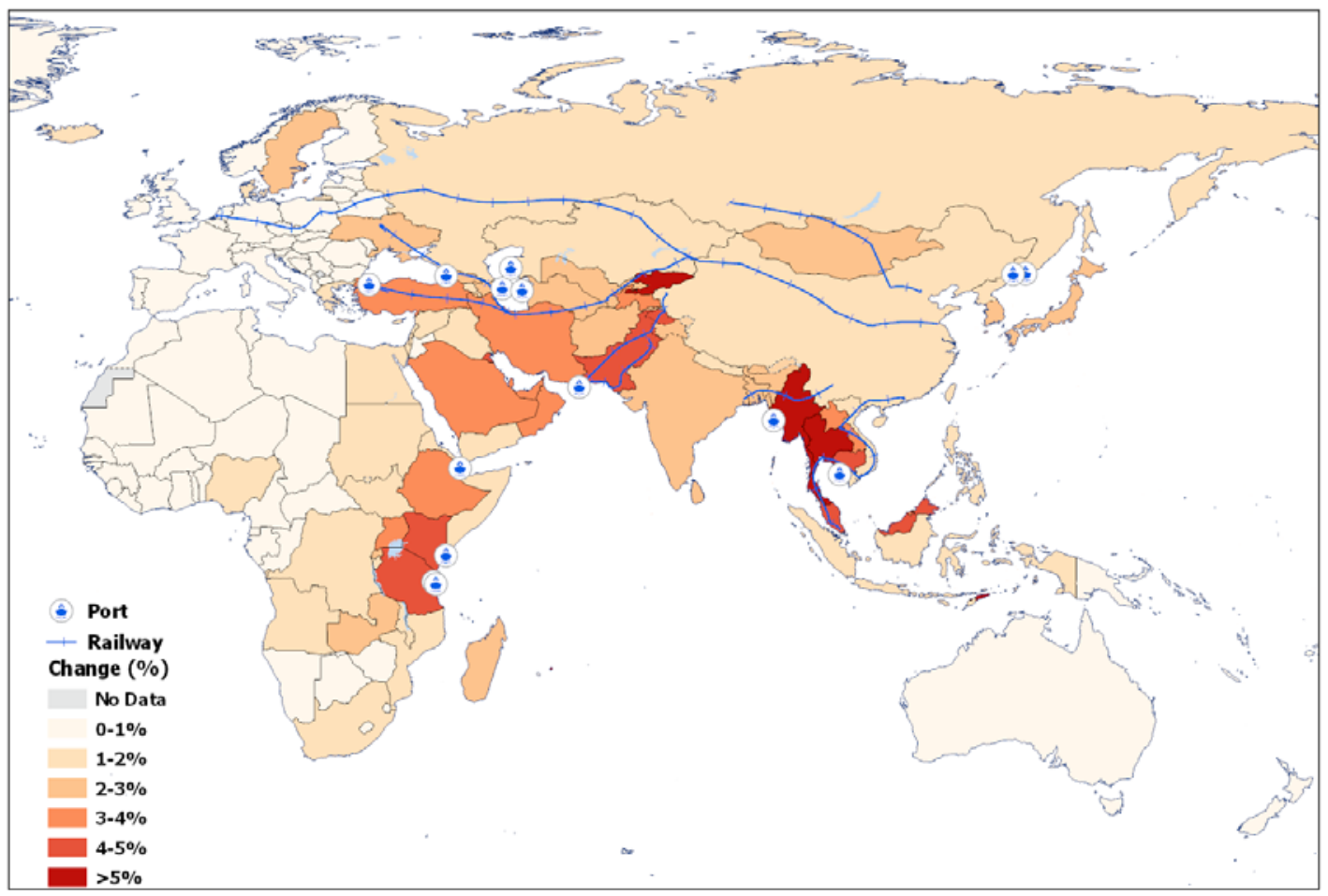

Note: For each country, all destinations are weighted by import flows.

The focus of this paper is the impact of BRI-related transport infrastructure projects on shipment times and trade costs. But the Belt and Road Initiative includes efforts to improve the efficiency of customs, reduce border delays or to improve management of economic corridors. As an extension of our main database, the supplemental appendix presents two scenarios where those elements are explicitly taken into account. In particular on two elements: the implementation of trade facilitation policies (proxied by a reduction in the border processing time) and the improvement of corridor management and decrease in congestion (proxied by a speed increase all along economic corridors). We find that the implementation of complementary policy reforms magnifies the impact on shipment times and trade costs, especially along the corridors.

\footnotetext{
${ }^{15}$ To further investigate our results, we also provide a series of additional analysis in the supplemental appendix
} where we aggregate gains for each economic corridors composing the Belt and Road Initiative. 


\section{Summary Statistics of all Variables}

a. Global Database

\begin{tabular}{|c|c|c|c|c|}
\hline Variables & Description & Min & Max & Mean \\
\hline origin & Origin country & - & - & - \\
\hline destination & Destination country & - & - & - \\
\hline sector & GTAP Sector & - & - & - \\
\hline Value_of_time_HS2 & $\begin{array}{l}\text { Value of time constructed using data from Hummels } \\
\text { and Schaur (2013) }\end{array}$ & 0.001 & 1.99 & 0.066 \\
\hline baseline_days_pre_BRI & $\begin{array}{l}\text { Population weighted distance in days between } \\
\text { origin and destination countries }\end{array}$ & 0 & 63.2 & 22.9 \\
\hline baseline_total_pre_BRI & $\begin{array}{l}\text { Total trade costs between origin and destination. } \\
\text { Trade costs include tariffs, transport and time costs. }\end{array}$ & 0 & 126.1 & 1.56 \\
\hline Change_Time_Lower & $\%$ decrease in time - lower bound scenario & 0 & 61.5 & 1.19 \\
\hline Change_Cost_Lower & $\%$ decrease in trade costs - lower bound scenario & 0 & 61.5 & 1.05 \\
\hline Change_Time_Lower_bdred & $\begin{array}{l}\% \text { decrease in time - lower bound scenario with } \\
\text { trade facilitation }\end{array}$ & 0 & 67.7 & 3.11 \\
\hline Change_Cost_Lower_bdred & $\begin{array}{l}\% \text { decrease in trade costs - lower bound scenario } \\
\text { with trade facilitation }\end{array}$ & 0 & 67.7 & 2.77 \\
\hline Change_Time_Lower_Corridors & $\begin{array}{l}\% \text { decrease in time - lower bound scenario with } \\
\text { improvements in corridor management }\end{array}$ & 0 & 61.5 & 1.29 \\
\hline Change_Cost_Lower_Corridors & $\begin{array}{l}\% \text { decrease in trade costs - lower bound scenario } \\
\text { with improvements in corridor management }\end{array}$ & 0 & 61.5 & 1.13 \\
\hline Change_Time_Upper & $\%$ decrease in time - upper bound scenario & 0 & 65.2 & 2.49 \\
\hline Change_Cost_Upper & $\%$ decrease in trade costs - upper bound scenario & 0 & 65.2 & 2.19 \\
\hline Change_Time_Upper_bdred & $\begin{array}{l}\% \text { decrease in time - upper bound scenario with } \\
\text { trade facilitation }\end{array}$ & 0 & 71.3 & 5.28 \\
\hline Change_Cost_Upper_bdred & $\begin{array}{l}\% \text { decrease in trade costs - upper bound scenario } \\
\text { with trade facilitation }\end{array}$ & 0 & 71.3 & 4.67 \\
\hline Change_Time_Upper_Corridors & $\begin{array}{l}\% \text { decrease in time - upper bound scenario with } \\
\text { improvements in corridor management }\end{array}$ & 0 & 65.8 & 4.11 \\
\hline Change_Cost_Upper_Corridors & $\begin{array}{l}\% \text { decrease in trade costs - upper bound scenario } \\
\text { with improvements in corridor management }\end{array}$ & 0 & 65.8 & 3.60 \\
\hline
\end{tabular}

\section{b. Regional Database}

\begin{tabular}{|c|c|c|c|c|}
\hline Variables & Description & Min & Max & Mean \\
\hline origin_city & Name of the origin city & - & - & - \\
\hline destination_city & Name of the destination city & - & - & - \\
\hline origin_country & Name of the origin country & - & - & - \\
\hline destination_country & Name of the destination country & - & - & - \\
\hline Change_Time_Lower & $\%$ decrease in time - lower bound scenario & 0 & 75.64 & 1.50 \\
\hline Change_Time_Upper & $\%$ decrease in time - upper bound scenario & 0 & 78.88 & 2.88 \\
\hline
\end{tabular}




\section{Conclusion}

This paper studies the effects of the Belt and Road Initiative on shipment times and trade costs for countries that are along the Belt and Road as proposed by China and for the world more broadly. The analysis combines detailed new information on transport infrastructure projects planned as part of the BRI, a GIS network model to precisely quantify the impact of these projects on shipping times, and estimates of the value of time from Hummels and Schaur (2013) to calculate the ad valorem equivalent reductions in trade costs. The key finding is that the Belt and Road Initiative can substantially reduce shipment times and trade costs for BRI economies (up to 3.2 and 2.8 percent, respectively) and for the world as a whole (up to 2.5 and 2.2 percent, respectively).

The main contribution of the paper is in the new methodology used to quantify changes in trade costs due to transport projects and the two novel databases that provide detailed information on BRI-induced changes in shipment times and trade costs for the world and for BRI economies. These data, in particular, will help researchers interested in better understanding the impact of the Belt and Road Initiative on a number of economic variables, including growth, trade, foreign investment, or the allocation of economic activity. The data may also be useful to investigate the systemic effects of BRI projects on non-economic variables such as air pollution or biodiversity or on social outcomes, such as the changes in poverty for certain groups in specific geographic locations.

Admittedly, this is a first look at the effects of the BRI on shipment times and trade costs and more research will be needed. First, on the data side, information on infrastructure projects linked to the Belt and Road Initiative will change -and, most likely, improve- over time. Second, on the methodological side, research may attempt to precisely model the choice between transport modes and how this choice is affected by BRI infrastructure projects. These developments would allow to improve the network analysis and provide more precise estimates.

Finally, this paper does not address two sets of important questions. First, we take BRI planned projects as given and do not investigate what network of infrastructure would maximize efficiency (in terms of reduction of shipment times and trade costs) for the set of BRI economies or the world. Second, we look at the impact of the infrastructure projects linked to the Belt and Road Initiative as a whole and do not attempt to identify the effects on shipment times and trade costs for, say, individual overland corridors such as the China Pakistan Economic Corridor (CPEC) or individual projects, such as the Gwadar Port. While the tools developed in this paper would help address these issues, both questions are left for future research.

\section{References}

1. Alder, S. (2017). Chinese Roads in India: The Effect of Transport Infrastructure on Economic Development. Unpublished Working paper.

2. Baniya, S. (2017). Effects of Timeliness on the Trade Pattern between Primary and Processed Goods. IMF Working Paper, WP/17/44.

3. Baniya, S., Rocha, N., and Ruta, M. (2019). Trade Effects of the New Silk Road: A Gravity Analysis. Policy Research working paper; no. WPS 8694. 
4. Bird, J., Lebrand, M., and Venables A. (2019). The Belt and Road Initiative: Reshaping Economic Geography in Central Asia? World Bank Policy Research working paper; no. WPS 8807.

5. Chen M. X. and Lin, C. (2018). Foreign Investment across the Belt and Road: Patterns, Determinants and Effects, World Bank Policy Research working paper; no. WPS 8607.

6. de Soyres, F., Mulabdic, A., and Ruta, M. (2019). Common Transport Infrastructure: A Quantitative Model and Estimates from the Belt and Road Initiative, World Bank Policy Research Working Paper; no. WPS 8801.

7. Djankov, S., Freund, C., and Pham, C. (2010). Trading on Time, The Review of Economics and Statistics, 92:1, pp. 166-173.

8. Donaldson D. (2018), Railroads of the Raj: Estimating the Impact of Transportation Infrastructure. American Economic Review, 108(4-5): pp. 899-934

9. Duranton, G., Morrow, P. and Turner, M. (2014), Roads and Trade: Evidence From the U.S., Review of Economic Studies, 2014, 81(2), 681-724

10. ESRI and United States Central Intelligence Agency (2012). Map of the World Oceans. [Washington, D.C.: Central Intelligence Agency, 2012] Map.

11. Hummels, D. (2001). Time as a Trade Barrier. Unpublished paper, Purdue University.

12. Hummels, D., Minor, P., Reisman, M. and Endean, E. (2007) Calculating Tariff Equivalents for Time in Trade. United States Agency for International Development (USAID).

13. Hummels, D., and Schaur, G. (2013). Time as a Trade Barrier, American Economic Review, 103(7): 2935-59.

14. Maliszewska M. and van der Mensbrugghe D. (2019). The Belt and Road Initiative: Economic, Poverty and Environmental Impacts. World Bank Policy Research working paper no. WPS 8814.

15. Minor, P. and Hummels, D. (2013) Time as a Barrier to Trade: A GTAP Database of Ad Valorem Trade Time Costs. ImpactEcon, 2nd Edition.

16. OECD (2017). ITF Transport Outlook 2017. OECD Publishing, Paris.

17. Reed, T. and Trubetskoy, S. (2019). Assessing the Value of Market Access from Belt and Road Projects. World Bank Policy Research working paper; no. WPS 8815.

18. Roberts, M., Deichmann, U., Fingleton, B., and Shi, T. (2010). On the Road to Prosperity? The economic geography of China's national expressway network. World Bank Policy Research Working Paper, no. 5479

19. Slack, B., Comtois, C., Wiegmans, B., and Witte, P. (2018). Ships Time in Port. International Journal of Shipping and Transport Logistics, Vol. 10, No. 1. pp.45 - 62

20. Volpe Martincus, C., Carballo, J., and Cusolito, A. (2017). Roads, Exports and Employment: Evidence From a Developing Country. Journal of Development Economics, vol. 125(C), pp. 21-39. 